\title{
General and specific characteristics \\ of communication competence of students of various medical specialties
}

N. V. Kopylova ${ }^{1}$, Y. V. Mikhaylyuk ${ }^{1}$

${ }^{1}$ Tver State University, 33 Zhelyabova str., Tver, 170100, Russian Federation

DOI: 10.18255/1996-5648-2021-4-624-629

Research article Full text in Russian

This article presents the results of a study of the general characteristics of communicative competence of students in medical specialties, manifested in a high level of sociability, the average level of formation of communicative control, the ability to manage emotions in communication, communicative tolerance and a low level of empathic abilities; specific characteristics are expressed in plasticity, trustworthiness, perseverance, curiosity and understanding.

Keywords: communicative competence; communicative culture; communicative skills; communicative setting; empathy; communicative tolerance

\section{INFORMATION ABOUT AUTHORS}

\author{
Kopylova, Natalia V. $\mid$ E-mail: Kopylova.NV@tversu.ru \\ Doc. Sc (Psychology), Professor \\ Mikhaylyuk, Yulia V. E-mail: mih-julia.80@mail.ru \\ Postgraduate
}




\title{
Общие и специфические характеристики коммуникативной компетентности студентов различных медицинских специальностей
}

\author{
Н. В. Копылова ${ }^{1}$ Ю. В. Михайлюк ${ }^{1}$
}

${ }^{1}$ Тверской государственный университет, ул. Желябова, 33, Тверь, 170100, Российская Федерация

DOI: $10.18255 / 1996-5648-2021-4-624-629$

УДК 159.9

Научная статья

Полный текст на русском языке

В данной статье представлены результаты исследования общих характеристик коммуникативной компетентности студентов медицинских специальностей, проявляющиеся в высоком уровне общительности, среднем уровне сорормированности коммуникативного контроля, умении управлять эмоциями в общении, коммуникативной толерантности и низком уровне эмпатических способностей; специфические характеристики выражаются в пластичности, доверчивости, настойчивости, любопытстве и понимании.

Ключевые слова: коммуникативная компетентность; коммуникативная культура; коммуникативные умения; коммуникативная установка; эмпатия; коммуникативная толерантность

\section{ИНФОРМАЦИЯ ОБ АВТОРАХ}

Копылова, Наталья Вячеславовна

Михайлюк, Юлия Васильевна
E-mail: Kopylova.NV@tversu.ru

Доктор психологических наук, профрессор

E-mail: mih-julia.80@mail.ru

Магистр психологических наук, аспирант

кафедры психологии

Введение компетентностного подхода в образование ориентирует на подготовку не только высокопрофессионального специалиста, но и личности, имеющей необходимый набор этических качеств, которые предполагают индивидуальное поведение в динамически изменяющихся условиях [1]. Одной из важных составляющих самореализации личности в современном обществе является коммуникативная компетентность, поскольку невозможно представить успешного человека без его тесных связей с социумом. Для специалиста медицинского профиля эта проблема приобретает особую актуальность в связи с высокой технической оснащенностью здравоохранения и возросшей медицинской грамотностью населения [2]. 
Копылова Н. В., Михайлюк Ю. В.

Под коммуникативной компетентностью врача понимается многоуровневое интегративное качество личности, направленное на установление, поддержание и развитие эффективных контактов с пациентами и другими участниками лечебно-профилактического процесса [3]. Формирование коммуникативной компетентности этого специалиста предполагает последовательную целенаправленную деятельность на всех этапах его подготовки.

С целью формирования коммуникативной компетентности проведено эмпирическое исследование, в котором приняли участие 713 студентов I-VI курсов УО «Белорусский государственный медицинский университет» г. Минска, обучающихся по специальностям «Стоматология», «Педиатрия», «Лечебное дело» и «Медико-профилактическое дело». В числе опрошенных 88 юношей и 625 девушек в возрасте от 16 до 29 лет.

Для изучения общих и специфических характеристик коммуникативной компетентности применялись методики: «Пятифакторный личностный опросник» (Р. МакКрае, П. Коста); «Диагностика оценки самоконтроля в общении» (М. Снайдер); “Диагностика коммуникативной установки» (В. В. Бойко); Тест «Уровень общительности» (В. Ф. Ряховский); «Исследования особенностей реагирования в конфликтной ситуации» (К. Томас); «Диагностика эмоциональных барьеров в межличностном общении» (В. В. Бойко); «Диагностика уровня эмпатических способностей» (В. В. Бойко); «Диагностика коммуникативной толерантности» (В.В.Бойко).

\section{Основная часть}

Изучение общих характеристик выявило, что у 75 \% студентов не сформированы способность к сопереживанию и сочувствию, направленность на восприятие и понимание другого человека, преобладает низкий уровень эмпатических способностей. Для $45 \%$ респондентов характерно проявление уважения, доброжелательности и терпимого отношения к пациентам; установление равноправных отношений, основанных на взаимном доверии, заинтересованности, стремлении понять другого; сдержанность при столкновении с некоммуникабельными качествами пациентов. У 51 \% студентов выявлен средний уровень общительности: студенты стремятся расширить круг своих знакомых, занимаются общественной деятельностью, помогают близким, друзьям, проявляют инициативу в общении, способны принять самостоятельное решение в трудной ситуации. Умение управлять эмоциями на высоком уровне отмечено у $33 \%$ студентов. Эмоциональные проблемы в повседневном общении наблюдаются у 41 \% студентов, у 26 \% испытуемых выявлено наличие эмоциональных барьеров в межличностном общении в контексте коммуникативной компетентности. Сформированность уровня коммуникативного контроля (средний и высокий уровни) наблюдается у 87 \% студентов. Эти студенты обладают способностью к эфрфективному межличностному взаимодействию, быстрому налаживанию контактов с окружающими и самостоятельному принятию решений. 
Общие и специфические характеристики коммуникативной компетентности...

Результаты общего среднего значения выше 33 \% свидетельствуют о наличии выраженной негативной коммуникативной установки. У студентов всех фракультетов была выявлена негативная комлуникативная установка. В меньшей степени она свойственна студентам лечебного фракультета, в большей - студентам медико-профилактического факультета. При выраженной негативной коммуникативной установке проблемы появятся даже при тщательной маскировке своего негативного настроения по отношению к окружающим. Субъекту приходится постоянно сдерживать себя и стараться быть корректным. Расплачиваться за это приходится высокой психологической ценой: рано или поздно состояние напряжения приведет к стрессу, нервному срыву, профессиональному выгоранию. Не исключено, что разрядка время от времени происходит за пределами работы - в семье, в общении с приятелями или в общественных местах. Таким образом, необходимо отметить тревожный симптом наличия негативной коммуникативной установки как предпосылки для профессионального эмоционального выгорания у студентов, которые ещё даже не начали свою профессиональную деятельность.

Использование однофакторного дисперсионного анализа в данном исследовании позволило выявить специббиеские характеристики коммуникативной компетентности у студентов-медиков в процессе обучения.

На протяжении обучения в университете у студентов снижается уровень пластичности и увеличивается уровень ригидности. Наиболее значимый переход от пластичности к ригидности наблюдается между первым и вторым курсом. Это можно объяснить происходящим становлением специалиста, а также формированием зрелости личности студентов. С годами их поведение становится более консервативным, привычным, устойчивым, при этом гибкость и податливость сменяются ригидностью.

В период со второго курса по четвертый студенты становятся менее общительными, но затем наблюдаются обратные изменения, когда с четвертого курса по шестой студенты вновь становятся более общительными. Можно предположить, что подобные изменения в уровне общительности у студентов напрямую связаны со сложностью обучения в университете: работа с большим объемом информации для самостоятельного изучения при подготовке к учебным дисциплинам и, как следствие, сложность получения знаний заставляют студентов сосредоточиваться на своих собственных проблемах.

Кроме того, для обучения в медицинском университете необходим довольно высокий уровень общего интеллектуального развития, в частности восприятия, представлений, памяти, мышления, внимания, эрудированности, широты познавательных интересов, уровня владения определенным кругом логических операций и, как результат, наблюдается недостаток времени для общения, а позже - возникающие трудности при межличностной коммуникации с одногруппниками, преподавателями, сотрудниками 
и пациентами. Однако на старших курсах привычный уровень общительности восстанавливается.

Отмечено, что у студентов в период обучения наблюдается тенденция к снижению уровня любопытства и увеличению консерватизма между первым и третьим курсами, затем к последнему курсу уровень консерватизма незначительно увеличивается. Можно предположить, что эти данные во многом связаны с естественным взрослением студентов, в процессе которого происходит снижение любознательности, любопытства, повышается серьезное отношение. В то же время большую роль в фрормировании постоянных привычек и интересов молодых людей играет учебный процесс, в рамках которого для достижения наилучших результатов от студентов традиционно требуется следование классическим правилам и нормам.

Обучающиеся на первом курсе чаще демонстрируют понимание других людей в сравнении с их товарищами, обучающимися на третьем - шестом курсах. Более понимающими людей являются студенты второго курса, в отличие от студентов третьего курса. Полученные результаты свидетельствуют о том, что по данной шкале прослеживается тенденция последовательного изменения от понимания к непониманию. Снижение уровня понимания у студентов можно объяснить необходимостью взаимодействовать с большим числом людей как в процессе обучения, так и на практике. В результате снижается возможность глубоко воспринимать поступающую от людей информацию, развиваются стереотипные представления о людях и их потребностях.

На протяжении обучения в университете у студентов также наблюдается снижение уровня открытости. Значимое изменение данного показателя происходит между первым и вторым курсами. Таким образом, студенты второго, третьего и старших курсов более замкнуты по сравнению со студентами первого курса. Снижение уровня открытости у студентов можно объяснить разрывом привычных связей, попаданием в новую среду, сложностями адаптации к образовательному процессу, необходимостью установления новых взаимоотношений с одногруппниками и преподавателями.

Полученные результаты позволяют констатировать неравномерный характер развития настойчивости у студентов. Данный показатель снижается от первых двух курсов к третьему, затем увеличивается на протяжении четвертого и пятого курсов и снова снижается на последнем курсе. При этом статистически значимое снижение уровня настойчивости происходит между вторым курсом и третьим, а повышение уровня данного показателя происходит между третьим курсом и пятым. Высокий уровень настойчивости на первых курсах университета студенты проявляют с целью достижения лучшей адаптации к новой среде. Настойчивость помогает им более успешно осваивать учебный материал и достигать высоких результатов в учебной деятельности. Но, достигнув определенных академических успехов, на третьем курсе они значительно снижают уровень настойчивости. Тем не менее на четвертом курсе возникает понимание 
о необходимости прилагать активные усилия для достижения высоких результатов в учебном процессе, научной и практикующей деятельности.

\section{Выводы}

Опираясь на результаты проведенного исследования, установлено, что в специфических характеристиках студентов медицинского университета на протяжении всего периода обучения наблюдаются неравномерные изменения. При переходе от первого курса ко второму у студентов снижается уровень уважения других людей, а также показатели пластичности, артистичности и любознательности, в то же время у них увеличивается уровень ригидности и реалистичности. Далее при переходе к третьему курсу увеличивается уровень практичности, консерватизма и равнодушия, снижаются показатели уровня теплоты и любопытства, при этом происходит переход от понимания других людей к их непониманию. Студенты четвёртого курса по сравнению со студентами младших курсов становятся более замкнутыми, снижается уровень сензитивности. Между четвертым и пятым курсами у студентов наблюдаются снижения в уровнях самообвинения и внутренней неустроенности, а к последнему шестому курсу у них снова увеличиваются показатели уровня общительности.

Следует отметить, что при переходе от первого курса ко второму у студентов наблюдается снижение уровня доверчивости и увеличение уровня подозрительности к людям, затем к третьему курсу происходит снижение уровня доминирования в межличностных отношениях, сотрудничества и настойчивости.

Установлено, что выраженность коммуникативной компетентности будущего врача опосредуется профилем медицинской специальности: студенты педиатрического и лечебного фракультетов имеют более высокую степень коммуникативной компетентности по сравнению с представителями стоматологического и медико-профилактического факультетов.

Принимая во внимание то, что коммуникативная компетентность будущего врача - одно из важных профессиональных качеств, необходимо целенаправленно проводить психологическую подготовку специалистов в ходе их обучения, обеспечивая фрормирование и развитие навыков общения и межличностного взаимодействия.

\section{Ссылки}

1. Баландина Е. В. Коммуникативная компетентность медицинских работников // Высшее образование в России. 2006. № 11. С. 152-153.

2. Беликова-Анкваб М. Ф., Каргиева З. К. О проблеме фрормирования профессиональной коммуникативной компетентности будущего врача в условиях региона // Научные проблемы гуманитарных исследований. 2011. № 11. С. 84-90.

3. Васильева Л. Н. Исследование коммуникативной компетентности студентов-медиков на стадии завершения обучения в вузе // Личность в современных исследованиях: сб. науч. тр. Вып. 11. Материалы VIII международной научно-практической конференции «Проблемы развития личности: психологическое консультирование и психотерапия». Рязань: Копи Принт, 2008. С. 159-164. 